\title{
Inovação no ensino: uma revisão sistemática das metodologias ativas de ensino-aprendizagem
}

\author{
Innovation in teaching: a systematic \\ review of active teaching-learning methodologies
}

Humberto Rodrigues Marques ${ }^{1}$
Alyce Cardoso Campos ${ }^{2}$
Daniela Meirelles Andrade ${ }^{3}$
André Luiz Zambalde ${ }^{4}$

Resumo: O aprendizado ativo constitui como um novo paradigma na educação de qualidade, colaborativa, envolvente e motivadora, corroborando no ensino-aprendizagem, dado que a educação não pode mais ser considerada uma prática simples. Diante dessa perspectiva, o presente trabalho tem por objetivo identificar como as metodologias ativas estão sendo aplicadas nas instituições de ensino atuais. Para tanto, foi realizada uma revisão sistemática de literatura sobre o conceito de métodos de ensino ativo nos últimos 10 anos. As descobertas oferecem recomendações teóricas, dado que proporciona um panorama acerca do tema, e práticas, uma vez que apresenta um primeiro caminho para os profissionais utilizarem esses métodos, como características, metodologias ativas existentes, disciplinas aplicáveis, entre outros.

Palavras-chave: Metodologia ativa. Ensino-aprendizagem. Revisão sistemática. 
Abstract: Active learning constitutes a new paradigm in quality, collaborative, engaging and motivational education, corroborating in teaching-learning, since education can no longer be considered a simple practice. From this perspective, the present work aims to identify how the active methodologies are being applied in the current teaching institutions. For this, a systematic literature review was conducted to verify how the concept of active teaching methods has been treated in the literature in the last 10 years. The findings provide theoretical recommendations, as it provides an overview of the subject, and practical recommendations, as it presents a first way for practitioners to use such methods, such as characteristics, existing active methodologies, applicable disciplines, among others.

Keywords: Active methodology. Teaching-learning. Systematic review.

\footnotetext{
${ }^{1}$ Universidade Federal de Lavras | Programa de Pós-Graduação em Administração | Lavras| MG | Brasil. Contato: hbetorm@hotmail.com. ORCID: 0000-0003-0557-8242

${ }^{2}$ Universidade Federal de Lavras | Programa de Pós-Graduação em Administração | Lavras| MG | Brasil. Contato: alyce.cardoso@gmail.com. ORCID: 0000-0001-6903-9542

${ }^{3}$ Universidade Federal de Lavras | Programa de Pós-Graduação em Administração | Lavras| MG | Brasil. Contato: daniela.andrade@ufla.br. ORCID: 0000-0001-7893-4629

${ }^{4}$ Universidade Federal de Lavras | Programa de Pós-Graduação em Administração | Lavras| MG | Brasil. Contato: zamba@dcc.ufla.br. ORCID: 0000-0003-0129-7451
}

DOI: http://dx.doi.org/10.1590/S1414-40772021000300005

Este é um artigo publicado em acesso aberto sob uma licença Creative Commons https://creativecommons.org/licenses/by-nc/4.0/ 


\section{Introdução}

Atualmente, a economia é marcada por mudanças industriais, globalização, aumento da competição, transferência de conhecimento, revolução da tecnologia da informação, reinvenção da sala de aula, assim como a necessidades de uma nova forma de aprendizagem (CIDRAL et al., 2017). Assim, verifica-se que o ensino superior mudou e necessita mudar mais, dado que a forma de ensino mais passiva e observadora, onde o estudante usualmente assiste aulas expositivas, não é mais funcional, dado que os alunos possuem diferentes tipos de processos de aprendizagem (MAIA, 2010; DIAS; SAUAIA; YOSHIZAKI, 2013).

A qualidade da aprendizagem nos dias atuais passa a ser sustentada pelo relacionamento pessoal do professor, no caso o facilitador, com o aluno, o ser que aprende em sala de aula, e não necessariamente nas habilidades pedagógicas, ou no planejamento curricular, ou na utilização de recursos audiovisuais, entre outros (ZANI; NOGUEIRA, 2006; CRUZ, 2017). Neste âmbito, a concepção construtivista emerge como uma forma de compreender a aprendizagem e o ensino como processos interativos inseparáveis (ALBUQUERQUE, 2016), onde a mudança das abordagens tradicionais para as construtivistas, no contexto da educação, corrobora para que essa temática seja um campo de pesquisa valioso para se entender as novas práticas educacionais (ALT, 2018).

Assim, o aprendizado ativo emerge como um novo paradigma para a oferta de educação de qualidade, colaborativa, envolvente e motivadora, com capacidade para responder à maioria dos desafios existentes nas instituições de ensino, demonstrando que a educação não pode ser considerada mais uma prática simples (MISSEYANNI et al., 2018). Ainda segundo esses autores, a prática de aprendizagem ativa se concentra em uma variedade de ferramentas usadas para envolver cognitivamente os alunos, acumulando conhecimento e desenvolvendo esquemas de uma forma que eles, em certa medida, possuem maior autonomia sobre a aprendizagem.

O aprendizado ativo, em relação aos métodos mais tradicionais, é mais eficaz por aumentar a compreensão dos alunos sobre conceitos difíceis de serem apreendidos (GUSC; VAN VEEN-DIRKS, 2017), principalmente quanto a abordagens didáticas caracterizadas pela memorização e pela compreensão abrangente de sistemas estáticos (MACVAUGH; NORTON, 2012). Neste âmbito os alunos participam de várias atividades, tais como leitura, discussão, redação e desenvolvimento de habilidades, das quais algumas das mais importantes são as de avaliação, reflexão, análise e síntese (DAOUK; BAHOUS; BACHA, 2016).

Assim, devido às mudanças de perfil do aluno, as instituições de ensino vêm adotando novas formas para o ensino-aprendizagem, tal como a utilização de metodologias mais ativas 
(FREITAS et al., 2002), corroborando na formação de profissionais como sujeitos sociais, desenvolvendo competências éticas, políticas e técnicas, aperfeiçoando o uso do conhecimento e do raciocínio crítico e analítico, assim como melhorando a aprendizagem e notas dos alunos (FORNI et al., 2017; VALES; SANTOS; 2018). Entretanto, devido aos diversos tipos de métodos existentes, é necessário que as instituições de ensino tomem decisões sobre qual método é mais adequado às suas respectivas realidades (NASCIMENTO, 2014; CAVALCANTE et al., 2018), assim como de uma maior profissionalização docente acerca dos diversos métodos (LÓPEZ et al., 2010; MACEDO et al., 2018). Para tanto, a implementação das metodologias mais ativas como forma de melhorar a aprendizagem ainda necessita de maiores estudos (MELO PRADO et al., 2011; SOBRAL; CAMPOS, 2012).

Dado que as metodologias ativas vêm mudar a realidade da sala de aula, faz-se necessário discutir o tema como forma de corroborar no seu desenvolvimento, já que muito se fala da necessidade de mudança na educação, sendo preciso investir em novos métodos para obter resultados nas futuras gerações. Assim, o presente estudo possui como objetivo identificar como as metodologias ativas estão sendo aplicadas nas instituições de ensino atuais. Para tanto, foi realizado uma revisão sistemática de literatura sobre o conceito de métodos de ensino ativo nos últimos 10 anos, utilizando o banco de dados ISI Web of Science® da Thomson Reuters. Procurar-se-á identificar as características dessa metodologia mais ativa, assim como as principais metodologias ativas empregadas em sala de aula, além das áreas de estudos que mais as aplicam, como forma de propor um panorama da área de estudo analisada.

Além desta introdução, o artigo possui mais cinco seções. A seguir é abordada a base teórica do estudo. Na terceira seção são apresentados os procedimentos metodológicos utilizados para atingir o objetivo proposto. Na quarta são apresentados os resultados, dividido na análise descritiva e na análise semântica dos dados. Por fim, as duas últimas seções representam as conclusões e as referências utilizadas na construção do estudo, respectivamente.

\section{0 uso de metodologias mais ativas para inovação no ensino}

O método tradicional de ensino centrado no professor ainda exerce grande influência no ensino, sendo fortemente utilizado na atualidade (MARIN et al., 2010), apesar de nem sempre ser adequado para gerar conhecimento e independência intelectual no estudante (VERGARA, 2003). Esse modelo positivista se baseia no mito da objetividade, através de modelos burocráticos e do movimento tecnicista do ensino que visam impedir interferências dos alunos no processo, possibilitando maior controle e padronização (MOURTHÉ JUNIOR; LIMA; PADILHA, 2018). A expectativa é que ocorram mudanças que tragam reais transformações e 
maiores resultados para a educação dos jovens (BARBOSA; MOURA, 2013), uma vez que apenas através de uma prática reflexiva, crítica e comprometida é possível proporcionar autonomia e enfrentar as resistências e conflitos encontrados (MITRE et al., 2008).

A educação formal ainda é concentrada no racionalismo e, com isso, o exercício educacional conservou-se no professor se apoiando em repetição, controle e disciplina (MOURTHÉ JUNIOR; LIMA; PADILHA, 2018). Para tanto, romper com o pensamento de fazer uso somente de métodos clássicos de ensino auxilia na superação do modelo tradicional de ensino-aprendizagem (MARIN et al., 2010). Entretanto, dilemas educacionais ainda são vivenciados, por um lado existem reflexões sobre a urgência de transformação dos modelos educacionais com o objetivo de desenvolver integralmente os estudantes e, por outro ainda há uma preservação do tradicionalismo no ensino sendo indiferente às descobertas de como as pessoas podem aprender (MOURTHÉ JUNIOR; LIMA; PADILHA, 2018).

Neste sentido, a educação atual requer uma atitude de corresponsabilidade com relação à aprendizagem, tendo a necessidade de um comprometimento mútuo entre docentes e discentes (URIAS; AZEREDO, 2017). É importante pensar em como os indivíduos aprendem, quais as condições necessárias e o papel do docente e das instituições de ensino nesse processo. É comum o professor saber o que ensinar, mas conseguir passar o conteúdo por fazer uso de uma pedagogia que não é adequada para o perfil dos discentes ou para o conteúdo (PINTO et al., 2012). Assim, além de conhecimento, os decentes devem ser capazes de aplicá-lo em diversas situações na sua esfera profissional (CHAMOSO; CÁCERES; AZCÁRATE, 2012).

Para atingir tal objetivo, pesquisas são realizadas de forma a analisar e desenvolver metodologias ativas de aprendizagem em que alunos sejam independentes e envolvam-se efetivamente nas atividades efetuadas em sala de aula (PINTO et al., 2012). Essas estratégias convidam o discente a se tornar um integrante ativo no exercício da aprendizagem, a desenvolver a maturidade cognitiva (AGLEN, 2015), a criatividade, o pensamento crítico e a construir seu próprio conhecimento (DEREVENSKAIA, 2014), promovendo um profundo e ativo aprendizado com o engajamento dos alunos (MCLEAN et al., 2016).

A utilização de métodos ativos evidencia a mudança de papel do estudante. Este precisa responsabilizar-se por sua aprendizagem, ser capaz de apresentar questionamentos relevantes para o contexto, além de buscar solucioná-los por meio de diferentes maneiras (MARIN et al., 2010). O professor passa a ser visto como um facilitador da aprendizagem, um parceiro que colabora com o aluno ajudando-o a compreender em vez de impor seu ponto de vista. Com isso, o aluno passa a ser um explorador autônomo que desenvolve opiniões e pensamentos próprios e não um mero reprodutor de ideias (SINGER; MOSCOVICI, 2008). 
Melo e Sant'Ana (2012) apresentam que o estudante não anseia do professor respostas, mas orientação e direcionamento quanto à busca e formação do seu próprio conhecimento o que torna esse saber sólido e duradouro. Proporcionar uma aprendizagem intensa exige primeiramente uma metodologia que consiga fazer com que o aluno se torne o protagonista de sua própria aprendizagem, fazendo-o abandonar o estado passivo, deixando de ser apenas espectador e passando a desenvolver o senso crítico e a capacidade de relacionar o conteúdo à realidade, tendo assim uma verdadeira produção de conhecimento (PINTO et al., 2012).

Barbosa e Moura (2013, p. 54) apresentam a famosa frase do filósofo Confúcio: "O que eu ouço, eu esqueço; o que eu vejo, eu lembro; o que eu faço, eu compreendo", tendo relação direta com a aprendizagem ativa ao incentivar a construção do conhecimento ao contrário de adquiri-lo de modo passivo do professor. Isso pode ser alcançado através de metodologias ativas que visam a proatividade, o desenvolvimento do raciocínio e a vinculação com a realidade (LIMA, 2017). Exemplos de metodologias ativas são a aprendizagem baseada em problemas (URIAS; AZEREDO, 2017), a espiral construtivista (LIMA, 2017), jogos educativos (MARCONDES, 2015), a aprendizagem entre pares (peerinstruction), a aplicação de métodos de caso e simulações que possibilitem a aprendizagem ativa (PINTO et al., 2012), entre outros.

A tecnologia também pode ser usada para uma melhor utilização do tempo e para aumentar a satisfação dos alunos com o conteúdo que lhes é proposto (MORGAN et al., 2015). Jovens e adolescentes têm uma atração por modernidade, podendo ser um bom meio para despertar a vontade de aprender. Educadores que projetam ambientes de aprendizagem interessantes fazem com que os discentes tenham níveis mais altos de satisfação, gerando maior envolvimento, aumentando o desempenho acadêmico e permanência dos alunos tanto em sala de aula quanto no curso (KILGOUR; GRUNDY; MONROUXE, 2016). Outra estratégia para incentivar interesse nos estudantes e fazer com que a aprendizagem seja relevante é associá-la a situações reais, tornando-a mais compreensível (AGLEN, 2015).

O uso de metodologias ativas pode ser considerado um auxílio na construção do conhecimento, refletindo em um avanço na formação dos estudantes (MARIN et al., 2010). Estas metodologias são vistas como grandes oportunidades de criação de resultados de aprendizagem positivos (MORGAN et al., 2015). Não se pode negar que é necessário enfrentar um grande obstáculo pedagógico da atualidade que são as tradicionais aulas expositivas, incorporando a aprendizagem ativa nas salas de aula e trazendo uma verdadeira mudança nas relações entre professor e aluno e na produção do conhecimento. Um questionamento que sempre deve ser feito é sobre quais práticas docentes são mais adequadas para atender às 
demandas na educação naquela ocasião e quais metodologias ativas podem contribuir para um aumento da eficiência e eficácia da aprendizagem (BARBOSA; MOURA, 2013).

\section{Procedimentos metodológicos}

Como forma de atingir o objetivo proposto na presente pesquisa, foi realizada uma revisão sistemática de literatura para coletar os dados do estudo, uma vez que sintetizar descobertas de pesquisas anteriores é uma das tarefas mais importantes para o avanço de uma linha específica de pesquisa (ZUPIC; CATER, 2015). Esse tipo de pesquisa, segundo Torraco (2005), é uma forma de pesquisa que revisa, critica e sintetiza a literatura representativa sobre um tema de forma integrada, de forma que novas estruturas e perspectivas sobre o tema são geradas. Como forma de expor a viabilidade da pesquisa, esta seção apresenta seu delineamento metodológico por meio de quatro fases: (1) procedimentos de busca e seleção; (2) critérios de seleção; (3) análise descritiva dos artigos; (4) análise semântica dos dados.

O procedimento de busca e seleção, que ocorreu no mês de julho de 2018, foi realizado no banco de dados ISI Web of Science ${ }^{\circledR}$ da Thomson Reuters, já que este repositório possui uma grande abrangência de documentos, é utilizado pelo meio acadêmico e organizacional, assim como possibilita meios para exportar e trabalhar os dados. A estratégia consistiu em

palavras-chave em inglês, sendo estas "active learning method*", "active teaching method*", "active method*" e "active learning-teaching method*", combinadas com as palavras "student*" e "teacher*", aplicadas no campo tópico da ISI Web of Science®, que engloba o título, resumo, palavras-chaves de autor e Keywords Plus da própria base. Operadores booleanos, assim como outros tipos de operadores, foram utilizados como forma de melhor refinar a pesquisa. A busca resultou em 772 artigos recuperados.

Com relação aos critérios seleção (Figura 1), adotou-se os seguintes procedimentos: (i) foram eliminados 408 artigos por não serem textos integrais publicados em periódicos; (ii) foram excluídos 154 artigos por não estarem publicados na língua inglesa e/ou por terem sido publicados antes de 2009, uma vez que considerou-se publicações dos últimos 10 anos; (iii) foram excluídos 79 artigos que não correspondiam à área de pesquisa da ISI Web of Science "pesquisas educacionais e educação"; (iv) foram excluídos 57 documentos, publicados em revistas com fator de impacto menor que 1; e, por fim, (v) foram excluídos 4 artigos por não corresponderem ao escopo da pesquisa. Assim, foram selecionados 70 artigos para a análise. 
Figura 1 - Desenho da pesquisa e processos

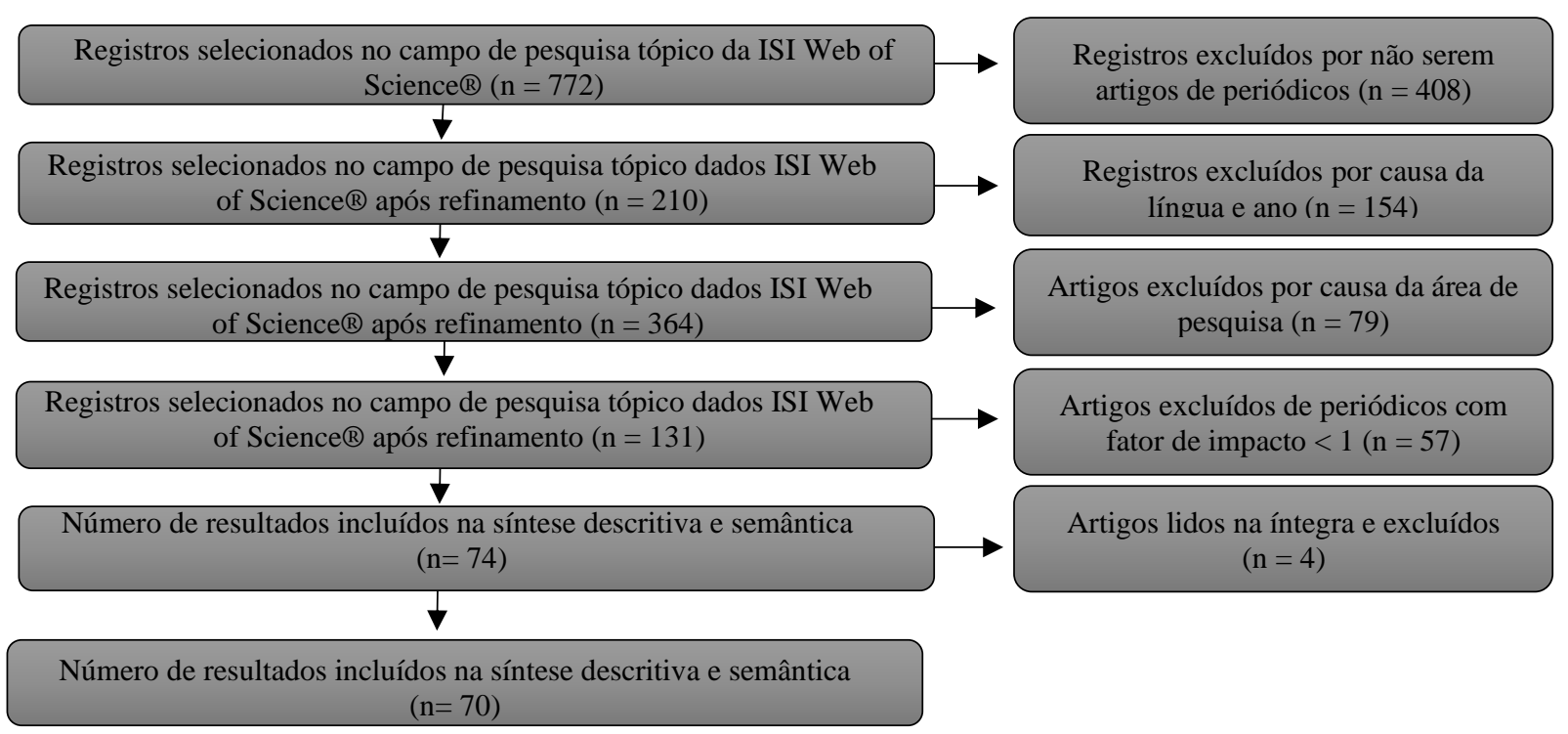

Fonte: Elaborado pelos autores.

A terceira fase consistiu na análise descritiva dos artigos, como forma de caracterizar os documentos analisados. Para tanto, os 70 artigos recuperados para análise foram tabulados em uma planilha eletrônica e foram sistematizados nas principais características dos artigos, (i) evolução de publicações; (ii) autores que mais publicaram; (iii) origem e área de pesquisa; (iv) revistas que mais publicaram; e (v) artigos mais citados da área.

A quarta fase representa a análise semântica, onde que foi realizada uma análise qualitativa dos artigos recuperados, onde os 70 artigos selecionados foram analisados com base em categorias de análise definidas a posteriori, como: (i) aspectos gerais da metodologia ativa; (ii) metodologias ativas encontradas nos artigos; e (iii) áreas de emprego das metodologias.

\section{Resultados}

\subsection{Análise descritiva}

Nesta seção apresenta-se uma visão geral acerca dos artigos selecionados. Com relação à publicação, por ano, dos 70 artigos, verifica-se, na Figura 2, que nos últimos anos as publicações acerca do tema foram maiores, dado que os anos de 2015 e julho de 2018 representaram cerca de $59 \%$ do total de publicações do período, demonstrando que a temática analisada é uma área que está crescendo e, por isso, se faz necessário ser analisada. 
Figura 2 - Evolução das publicações por ano

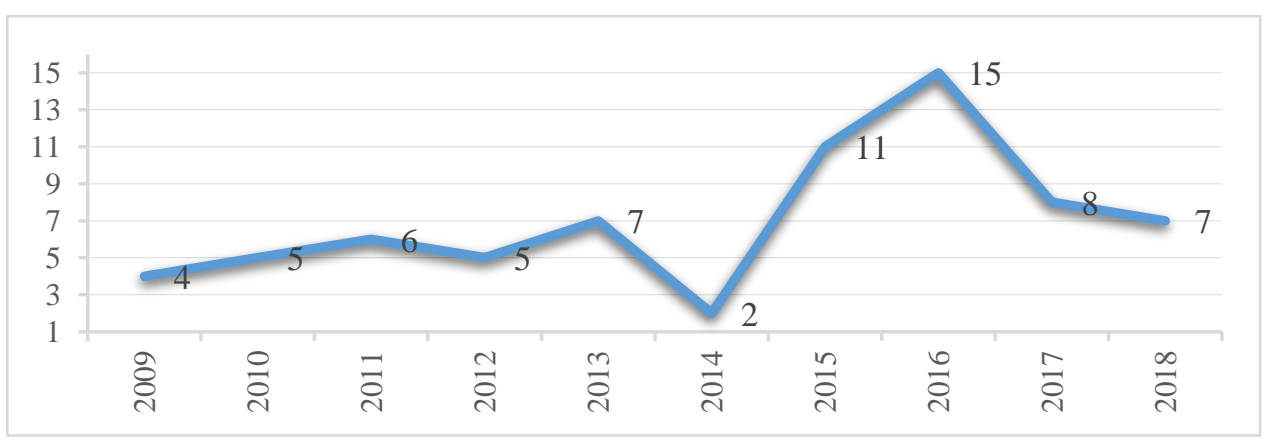

Fonte: Dados da pesquisa.

Os 5 periódicos que mais publicaram sobre o tema (Tabela 1), representam $50 \%$ de todas as publicações analisadas e possuem como escopo de publicação o tema relacionado com educação e suas variações. Destaca-se que dentre os 5 periódicos, 3 estão relacionados com a área da saúde, demonstrando ser esta uma área com grande interesse em novas metodologias ativas e métodos alternativos para profissionalizar seus estudantes (FATMI et al., 2013).

Tabela 1 - Periódicos com maior frequência de publicações

\begin{tabular}{lcc}
\hline Periódicos & Frequência & $\%$ \\
\hline Advances in Physiology Education & 10 & 14,29 \\
American Journal of Pharmaceutical Education & 8 & 11,43 \\
Computers Education & 6 & 8,57 \\
IEEE Transactions on Education & 6 & 8,57 \\
BMC Medical Education & 5 & 7,14 \\
\hline
\end{tabular}

Fonte: Dados da pesquisa.

Os artigos selecionados, como apresentado na metodologia, correspondem à área de pesquisa de Educação e Pesquisa Educacional, porém, verifica-se que, como os estudos podem ser classificados em mais de uma classificação, que 14,28\% também foram classificados como engenharia e como psicologia, 11,43\% como farmacologia e farmácia, 10\% como Ciências da Computação, 8,57 \% com Ciências e serviços da saúde, além de outras. Com observa-se, o tema de pesquisa estudado pode ser analisado em diversos contextos, demonstrando a sua amplitude outras áreas de pesquisa, o que demonstra que esta perspectiva de pesquisa pode ser utilizada em outros contextos, como forma de analisar outros objetos de estudo.

Com relação aos autores que mais publicam sobre o tema, verifica-se de acordo com o Quadro 1, que apenas dois autores possuíram 3 artigos publicados, sendo estes Fernanda K. Marcondes, da Universidade Estadual de Campinas no Brasil, e Luis Henrique Montrezor, da 
Universidade de Araraquara no Brasil. Além dos dois pesquisadores brasileiros identificados, enfatiza-se que um autor possui apenas dois artigos publicados sobre o tema e outros 242 autores possuem apenas uma publicação sobre a temática. Evidencia-se, assim, ser este um campo multidisciplinar, possivelmente com produções pontuais, não havendo um histórico de um determinado pesquisador que desenvolve pesquisas aplicadas nesta área.

Quadro 1 - Autores que mais publicaram na área

\begin{tabular}{|c|c|c|c|}
\hline Autores & Artigo & Periódico & Ano \\
\hline \multirow{3}{*}{$\begin{array}{l}\text { Marcondes, } \\
\text { Fernanda K. }\end{array}$} & A puzzle used to teach the cardiac cycle & $\begin{array}{l}\text { Advances in } \\
\text { Physiology Education }\end{array}$ & 2015 \\
\hline & $\begin{array}{l}\text { Effect of an educational game on university students' } \\
\text { learning about action potentials }\end{array}$ & $\begin{array}{l}\text { Advances in } \\
\text { Physiology Education }\end{array}$ & 2017 \\
\hline & $\begin{array}{l}\text { Meeting report: IUPS and ADInstruments } 2017 \text { Teaching } \\
\text { Workshop }\end{array}$ & $\begin{array}{l}\text { Advances in } \\
\text { Physiology Education }\end{array}$ & 2018 \\
\hline \multirow{3}{*}{$\begin{array}{l}\text { Montrezor, } \\
\text { Luis Henrique }\end{array}$} & A puzzle used to teach the cardiac cycle & $\begin{array}{l}\text { Advances in } \\
\text { Physiology Education }\end{array}$ & 2015 \\
\hline & $\begin{array}{l}\text { Performance in physiology evaluation: possible } \\
\text { improvement by active learning strategies }\end{array}$ & $\begin{array}{l}\text { Advances in } \\
\text { Physiology Education }\end{array}$ & 2016 \\
\hline & $\begin{array}{l}\text { Effect of an educational game on university students' } \\
\text { learning about action potentials }\end{array}$ & $\begin{array}{l}\text { Advances in } \\
\text { Physiology Education }\end{array}$ & 2017 \\
\hline
\end{tabular}

Fonte: Dados da pesquisa.

Quanto às instituições de pesquisas com maior quantidade de publicações sobre o tema pesquisado foram, segundo a Tabela 2, Universidade de Limerick, com 3 trabalhos publicados, sediada na Irlanda, e Universidade Estadual de Campinas e Universidade de Araraquara, ambas instituições de ensino brasileiras também com 3 trabalhos publicados. Ainda outras 6 instituições de ensino tiveram 2 trabalhos, assim como outras 121 instituições possuíram apenas uma publicação sobre o tema. Enfatiza-se que dentre as instituições que mais publicam, 3 são de origem espanhola e outras 3 de origem brasileira, demonstrando que estes países possuem uma centralidade de universidades que se destinam a pesquisar essa temática.

Tabela 2 - Instituições de pesquisa com maior frequência de publicações

\begin{tabular}{lcc}
\hline Periódicos & Frequência & $\%$ \\
\hline Universidade de Limerick & 3 & 4,28 \\
Universidade Estadual de Campinas & 3 & 4,28 \\
Universidade de Araraquara & 3 & 4,28 \\
Universidade de Purdue & 2 & 2.86 \\
Universidade do País de Basco & 2 & 2.86 \\
Universidade de Leon & 2 & 2.86 \\
Universidade Politécnica de Madri & 2 & 2.86 \\
Universidade de São Paulo & 2 & 2.86 \\
Universidade de Sevilha & 2 & 2.86 \\
\hline
\end{tabular}

Fonte: Dados da pesquisa. 
Com relação à origem dos 70 trabalhos selecionados para análise, verifica-se que 34,29\% correspondem aos Estados Unidos, 24,29\% à Espanha, 11,43\% ao Brasil e 5,71\% à Austrália, ao Canadá e à Irlanda. Ainda, enfatiza-se que outros 4 países possuíram 2 publicações cada e 14 possuíram apenas uma publicação.

Por fim, apresenta-se na Tabela 3 os 10 trabalhos mais citados. Enfatiza-se que estes 10 trabalhos correspondem a aproximadamente 53\% do total de citações de todos os trabalhos selecionados, demonstrando a relevância dos mesmos em relação ao total da amostra.

Tabela 3 -10 trabalhos mais citados da área

\begin{tabular}{|c|c|}
\hline Qnt & Referências \\
\hline 51 & $\begin{array}{l}\text { STEWART, D. W. et al. Active-learning processes used in US pharmacy education. American jour- } \\
\text { nal of pharmaceutical education, Arlington, v. } 75 \text {, n. } 4 \text {, p. } 68,2011 \text {. }\end{array}$ \\
\hline 42 & $\begin{array}{l}\text { REGUERAS, L. M. et al. Effects of competitive e-learning tools on higher education students: A } \\
\text { case study. IEEE Transactions on Education, London, v. 52, n. 2, p. 279-285, } 2009 .\end{array}$ \\
\hline 39 & $\begin{array}{l}\text { FATMI, M. et al. The effectiveness of team-based learning on learning outcomes in health profes- } \\
\text { sions education: BEME Guide. Medical teacher, Dundee, v. } 35, \text { n. } 12 \text {, p. e1608-e1624, } 2013 \text {. }\end{array}$ \\
\hline 33 & $\begin{array}{l}\text { CONSORTI, F. et al. Efficacy of virtual patients in medical education: a meta-analysis of randomized } \\
\text { studies. Computers \& Education, United Kingdom, v. 59, n. 3, p. 1001-1008, } 2012 .\end{array}$ \\
\hline 33 & $\begin{array}{l}\text { ZINGONE, M. M. et al. Comparing team-based and mixed active-learning methods in an ambulatory } \\
\text { care elective course. American journal of pharmaceutical education, Arlington, v. } 74 \text {, n. 9, p. 160, } \\
2010 \text {. }\end{array}$ \\
\hline 31 & $\begin{array}{l}\text { MENEKSE, M. et al. Differentiated overt learning activities for effective instruction in engineering } \\
\text { classrooms. Journal of Engineering Education, Washington, v. } 102 \text {, n. 3, p. 346-374, } 2013 \text {. }\end{array}$ \\
\hline 26 & $\begin{array}{l}\text { TAN, N. CK et al. A controlled study of team-bas } \\
\text { education. BMC medical education, United Kingc }\end{array}$ \\
\hline 22 & $\begin{array}{l}\text { MCLEAN, S. et al. Flipped classrooms and student learning: not just surface gains. Advances in } \\
\text { physiology education, Rockville, v. } 40, \text { n. } 1, \text { p. } 47-55,2016 \text {. }\end{array}$ \\
\hline 21 & $\begin{array}{l}\text { LÓPEZ, J. M. S.; GONZÁLEZ, M. R.; CANO, E. V. Visual programming languages integrated } \\
\text { across the curriculum in elementary school: A two year case study using "Scratch" in five schools. } \\
\text { Computers \& Education, United Kingdom, v. } 97 \text {, p. 129-141, } 2016 .\end{array}$ \\
\hline 21 & $\begin{array}{l}\text { BAGHCHEGHI, N.; KOOHESTANI, H. R.; REZAEI, K. A comparison of the cooperative learning } \\
\text { and traditional learning methods in theory classes on nursing students' communication skill with pa- } \\
\text { tients at clinical settings. Nurse education today, United Kingdom, v. } 31 \text {, n. } 8, \text { p. } 877-882,2011 \text {. }\end{array}$ \\
\hline
\end{tabular}

Fonte: Dados da pesquisa.

\subsection{Análise semântica}

Essa subseção tem por objetivo discutir as principais características relacionadas com o tema analisado. Para tanto, primeiramente abordar-se-á os aspectos gerais relacionados com a metodologia ativa, tais como algumas características, vantagens e dificuldades. Em seguida serão apresentadas e caracterizadas as principais metodologias ativas encontradas, assim como os autores que as abordam em seus estudos. Por fim, serão demonstradas as áreas de estudo que mais utilizam a abordagem de metodologia ativa, como forma de apresentar as áreas que mais demandas possuem quanto ao aperfeiçoamento do ensino-aprendizagem do aluno. 


\subsubsection{Aspectos gerais da metodologia ativa}

O aprendizado ativo cria um ambiente de classe mais aberto e imprevisível do que em uma aula baseada em palestras, onde o conteúdo e o ritmo são estritamente controlados (CARPEÑO et al., 2011). Aprender fazendo motiva os alunos e permite que eles desenvolvam estratégias orientadas para a solução de problemas, implicando em uma abordagem de ensino e aprendizagem baseada na obtenção de conhecimentos e habilidades focada no processo educacional de modo mais dinâmico (LÓPEZ; GONZÁLEZ; CANO, 2016).

A combinação da aula teórica com ferramentas de aprendizagem ativa pode ser útil para que os alunos compreendam melhor e esclareçam equívocos sobre o tema estudado, de modo que alguns tópicos não entendidos podem se tornar mais compreensíveis (MARCONDES et $a l .$, 2015). Srivastava e Tait (2012) evidenciaram que a série de atividades ativas empregadas em sala de aula permitiu que os alunos desenvolvessem suas habilidades essenciais, demonstrando-as através de uma explicação dos principais conceitos apreendidos, assim como promovessem suas habilidades de análise crítica e analítica (SRIVASTAVA; TAIT, 2012).

Para tanto, verifica-se benefícios não apenas na experiência de aprendizagem, mas também no desempenho, especialmente para aqueles alunos que estão tendo mais dificuldade em dominar o currículo (KRUPAT et al., 2016). Neste sentido, González-Sancho et al. (2013) e Arbelaitz et al. (2015) ao analisarem a transição de um curso centrado em instrutores e baseado em palestras, para um curso centrado no aluno e baseado em metodologias ativas, verificaram que a implementação do aprendizado ativo resultou em uma grande melhoria tanto na aprovação quanto nas notas gerais. García e Hernandez (2010) evidenciaram que os alunos que participaram de atividades de metodologia ativa obtiveram melhores resultados do que grupos de alunos que não participaram, melhorando em até $50 \%$ a mais na aprovação no curso.

De acordo os resultados de Gahutu (2010), os alunos parecem apreciar o sistema ativo, dado que a maioria dos alunos se mostra entusiasmada, assim como solicitam mais tempo para isso, apesar de essa nova experiência de ensino ser percebida negativamente por alguns alunos, que ainda são dependentes do aprendizado tradicional em sala de aula. Ainda, como elucidam Rivkin e Gim (2013) e Arbelaitz et al. (2015), os alunos preferem aprender realizando um projeto real, uma vez que corrobora no desenvolvimento algumas competências interdisciplinares, apesar de ficarem preocupados com o aumento da carga de trabalho e do esforço associado ao material de aprendizagem antes da aula. Assim, é importante que os resultados da implementação de metodologias ativas sejam alcançados sem sobrecarregar os alunos, dado que seus benefícios não necessariamente dependem de uma carga de trabalho excessiva (GONZÁLEZ-SANCHO et al., 2013). Deste modo, para que as atividades mais 
ativas de ensino não possuam resistência por parte dos alunos, elas devem estar bem integradas com todos os participantes, assim como não devem demandar um aumento muito significativo na carga de trabalho desses estudantes.

A implementação bem-sucedida dessas metodologias envolve mudanças em uma parte significativa do processo de ensino, desde o design instrucional e a organização, até o desenvolvimento de materiais didáticos, assim como a atividade do professor dentro da sala de aula (CARPEÑO et al., 2011). Segundo Marcondes (2015), o papel fundamental da universidade, além da comunicação, é gerar conhecimento, formando recursos humanos que respondam às necessidades da sociedade, de modo que essa tarefa seria mais fácil se os professores utilizassem diferentes estratégias de ensino. Deste modo, Bunting e Cheville (2009) evidenciam que as mudanças no aprendizado do aluno tornaram-se mais positivas e significativas à medida que o corpo docente se torna mais eficiente em usar o aprendizado ativo.

A principal desvantagem na incorporação desse tipo de metodologia ativa é o esforço da equipe docente (GARCÍA; HERNANDEZ, 2010), dado que os professores necessitam dedicar mais tempo ao ensino, aumentando a carga de trabalho, já que é necessário preparar trabalho em grupo, tutoriais organizados, leitura e avaliação de relatórios, entre outros (REYES; GÁLVEZ, 2010). Entretanto, Rivkin e Gim (2013) enfatizam que apesar de o exercício de aprendizagem ativa ser um desafio inicialmente, a carga de trabalho dos docentes deve diminuir com o aumento da experiência (RIVKIN; GIM, 2013). Assim, Mccormack e O'flaherty (2010) salientam que deve-se reconhecer que essas dificuldades enfrentadas pelos professores estão relacionadas com a falta de profissionalização dos mesmos, relacionado com a sua formação.

\subsubsection{Metodologias ativas encontradas nos artigos}

$\mathrm{Na}$ maioria das universidades em todo o mundo, o assunto passado para os alunos é conduzido por meio de palestras tradicionais em sala de aula (GARCÍA; HERNANDEZ, 2010). No entanto, verifica-se que os alunos possuem diferentes estilos de aprendizagem, de modo que é necessário utilizar diferentes estratégias de ensino, como forma de melhorar a retenção de conhecimento e o aprendizado efetivo dos alunos, proporcionando ao professor a possibilidade de envolver alunos com diversos estilos de aprendizagem (MARCONDES et al., 2015). Para tanto, a seguir, apresenta-se uma análise das principais metodologias ativas encontradas nos trabalhos selecionados, de forma que o Quadro 2 resume os resultados encontrados. 
Quadro 2 - Principais metodologias ativas encontradas

\begin{tabular}{|c|c|c|}
\hline $\begin{array}{l}\text { Metodologia } \\
\text { Ativa }\end{array}$ & Descrição & $\begin{array}{c}\text { Autores que } \\
\text { utilizam }\end{array}$ \\
\hline $\begin{array}{l}\text { Aprendizagem } \\
\text { cooperativa }\end{array}$ & $\begin{array}{l}\text { É um método que tem benefícios sociais e acadêmicos, que envolve, } \\
\text { na maioria das vezes, pequenos grupos de alunos que contribuem para } \\
\text { a aprendizagem uns dos outros, permitindo que os alunos tragam sua } \\
\text { própria experiência para o processo de aprendizagem e aumentem o } \\
\text { aprendizado ativo, assim como encoraja a criatividade, estimula a } \\
\text { discussão e melhora a confiança e o desempenho, promovendo o } \\
\text { raciocínio crítico e a capacidade de síntese e análise (REYES; } \\
\text { GÁLVEZ, 2010; BAGHCHEGHI; KOOHESTANI; REZAEI, 2011). }\end{array}$ & $\begin{array}{l}\text { Reyes e Gálvez } \\
\text { (2010); } \\
\text { Baghcheghi, } \\
\text { Koohestani e } \\
\text { Rezaei (2011). }\end{array}$ \\
\hline $\begin{array}{l}\text { Aprendizagem } \\
\text { baseada em } \\
\text { equipe }\end{array}$ & $\begin{array}{l}\text { É um método de aprendizagem cooperativa, onde apenas os alunos } \\
\text { discursam, sem a intromissão do professor, que supervisiona as } \\
\text { discussões (ZINGONE et al., 2010; FATMI et al., 2013). Como } \\
\text { apresentam Tan et al. (2011), esse método envolve três passos: (i) os } \\
\text { alunos devem ler o material preparatório fora da sala da de aula; (ii) } \\
\text { cada aluno realiza um teste para avaliar se apreenderam os } \\
\text { conhecimentos e os conceitos da primeira etapa, assim como, após } \\
\text { serem agrupados aleatoriamente em grupos de } 5 \text { a } 7 \text { alunos, realizam, } \\
\text { novamente o teste; e (iii) os grupos trabalham em tarefas onde é } \\
\text { possível aplicar o conhecimento adquirido nas fases } 1 \text { e } 2 \text {. }\end{array}$ & $\begin{array}{l}\text { Zingone } \text { et al. } \\
\qquad(2010) ; \\
\text { Tan et al. }(2011) \\
\text { Fatmi et al. }(2013) \text {; } \\
\text { Krupat et al. } \\
\quad(2016) \text {. }\end{array}$ \\
\hline $\begin{array}{l}\text { Aprendizagem } \\
\text { baseada em } \\
\text { casos }\end{array}$ & $\begin{array}{l}\text { Coloca os alunos frente a frente com casos da vida real, de forma que } \\
\text { analisem situações e apresentem soluções profissionais, sendo } \\
\text { tomadores de decisões, desenvolvendo determinadas competências } \\
\text { interdisciplinares que são muito valorizadas no mundo profissional, } \\
\text { como trabalho em equipe, planejamento, comunicação e pensamento } \\
\text { crítico (ARRUE; CABALLERO, 2015). }\end{array}$ & $\begin{array}{c}\text { Arrue e Caballero } \\
\text { (2015); McFee } \text { et } \\
\text { al. }(2018) .\end{array}$ \\
\hline $\begin{array}{l}\text { Aprendizagem } \\
\text { colaborativa } \\
\text { baseada em } \\
\text { casos }\end{array}$ & $\begin{array}{l}\text { Foca em pequenos grupos com princípios de aprendizagem baseados } \\
\text { em equipe e incorpora elementos de aprendizagem baseada em } \\
\text { problemas (PBL) e aprendizado baseado em casos, onde inclui um } \\
\text { processo de garantia de prontidão pré-classe e atividades baseadas em } \\
\text { casos em que os alunos respondem a perguntas abertas, onde discutem } \\
\text { suas respostas em grupos menores e, em seguida, chegam a um } \\
\text { consenso em grupos maiores (KRUPAT et al., 2016). }\end{array}$ & $\begin{array}{l}\text { Krupat et al. } \\
\qquad(2016) .\end{array}$ \\
\hline $\begin{array}{l}\text { Aprendizagem } \\
\text { baseada em } \\
\text { projetos }\end{array}$ & $\begin{array}{l}\text { É um método de aprendizagem baseado no desenvolvimento de } \\
\text { projetos, nos quais os alunos planejam, implementam e avaliam } \\
\text { projetos que têm aplicação no mundo real (DOMÍNGUEZ; JAIME, } \\
\text { 2010). É centrada no aluno, em que os professores atuam como guias, } \\
\text { de forma que integra conteúdo e habilidade, ajudando os alunos a } \\
\text { conhecer e fazer (ARBELAITZ et al., 2015). }\end{array}$ & $\begin{array}{l}\text { Domínguez e Jaime } \\
\text { (2010); Arbelaitz et } \\
\text { al. (2015); Seman } \\
\text { et al. }(2018) .\end{array}$ \\
\hline $\begin{array}{l}\text { Aprendizagem } \\
\text { baseada em } \\
\text { problema }\end{array}$ & $\begin{array}{l}\text { Nesta abordagem os estudantes são confrontados com um problema } \\
\text { aberto, mal estruturado e autêntico relacionado ao mundo real } \\
\text { (VALENZUELA-VALDÉS et al., 2016). Os estudantes assumem mais } \\
\text { responsabilidade por sua própria aprendizagem e organizam atividades } \\
\text { sob a orientação de um tutor, de forma que pode melhorar o } \\
\text { conhecimento do conteúdo e fomentar o desenvolvimento da } \\
\text { comunicação, resolução de problemas e habilidades de aprendizagem } \\
\text { auto direcionadas, fornecendo, assim, um valor acrescentado à } \\
\text { aprendizagem autónoma dos alunos (GARCÍA; HERNANDEZ, 2010). }\end{array}$ & $\begin{array}{c}\text { García e Hernandez } \\
\text { (2010); Melo Prado } \\
\text { et al. }(2011) ; \\
\text { Azzalis } \text { et al. } \\
\text { (2012); Rivkin e } \\
\text { Gim (2013); De } \\
\text { Justo e Delgado } \\
\text { (2015); Leite } \text { et al. } \\
\text { (2015); Borrell et } \\
\text { al. (2016); } \\
\text { Valenzuela-Valdés } \\
\text { et al. } \text { (2016); } \\
\text { Rodriguez-Andara } \\
\text { et al. } \text { (2018). }\end{array}$ \\
\hline
\end{tabular}




\begin{tabular}{|c|c|c|}
\hline $\begin{array}{l}\text { Sala de aula } \\
\text { invertida }\end{array}$ & $\begin{array}{l}\text { Reaproveita o tempo de aula para se concentrar na aplicação e } \\
\text { discussão, onde a aquisição de conceitos e princípios básicos é feita } \\
\text { pelo aluno antes da aula. Os alunos participam de trabalhos } \\
\text { preparatórios, que podem incluir o uso de palestras, leituras ou } \\
\text { módulos on-line pré-gravados, de modo que o tempo de aula é então } \\
\text { redirecionado para se concentrar na resolução de problemas, aplicação, } \\
\text { síntese e aprendizado colaborativo (MCLEAN et al., 2016). }\end{array}$ & $\begin{array}{l}\text { Luker et al. }(2015) \text {; } \\
\quad \text { Mclean } \text { et al. } \\
\quad(2016) ; \\
\text { Kaila et al. }(2016) ; \\
\quad \text { MacDougall } \\
\quad \text { (2017). }\end{array}$ \\
\hline $\begin{array}{c}\text { Jogos } \\
\text { educativos }\end{array}$ & $\begin{array}{l}\text { Um jogo educativo pode ser uma atividade competitiva com regras e } \\
\text { procedimentos nos quais a aprendizagem resulta de interações e } \\
\text { comportamentos dos jogadores, assim como uma simulação baseada } \\
\text { na realidade ou em uma atividade não competitiva estruturada. Os } \\
\text { jogos educativos propiciam que alunos consigam aprender fazendo, de } \\
\text { modo que consigam desenvolver sua criatividade e capacidade de } \\
\text { solucionar problemas, assim como melhorar sua comunicação e } \\
\text { negociação com os colegas (MARCONDES et al., 2015). }\end{array}$ & $\begin{array}{l}\text { Marcondes et al. } \\
\text { (2015); Montrezor } \\
\text { (2016); Luchi, } \\
\text { Montrezor e } \\
\text { Marcondes (2017); } \\
\text { Spencer e Bandy } \\
\text { (2018). }\end{array}$ \\
\hline Scratch & $\begin{array}{l}\text { É considerado uma mídia de código aberto, que permite o aluno criar } \\
\text { e desenvolver programas, jogos, interfaces e apresentações que possam } \\
\text { ampliar a compreensão de conceitos e práticas computacionais. } \\
\text { Propicia um método intuitivo de arrastar e soltar de programação que } \\
\text { permite aos usuários explorar e criar ambientes educacionais (LÓPEZ; } \\
\text { GONZÁLEZ; CANO, 2016). }\end{array}$ & $\begin{array}{l}\text { López, González e } \\
\text { Cano (2016). }\end{array}$ \\
\hline $\begin{array}{l}\text { Sistema } \\
\text { QUEST }\end{array}$ & $\begin{array}{l}\text { É uma ferramenta baseada em tecnologias de informação, cujo objetivo } \\
\text { é a introdução de workshops cooperativos e competitivos, promovendo } \\
\text { o desenvolvimento de habilidades de pesquisa, documentação e análise } \\
\text { crítica, aumentando o nível de envolvimento e comunicação entre } \\
\text { alunos e professores (REGUERAS et al., 2009). }\end{array}$ & $\begin{array}{l}\text { Regueras et al. } \\
\text { (2009). }\end{array}$ \\
\hline $\begin{array}{l}\text { Pacientes } \\
\text { virtuais }\end{array}$ & $\begin{array}{l}\text { São simulações de casos clínicos baseados em computador, onde os } \\
\text { usuários interagem com o sistema e treinam suas habilidades de } \\
\text { raciocínio clínico, superando o acesso reduzido dos estudantes a } \\
\text { pacientes reais, bem como um ambiente estruturado e seguro para os } \\
\text { estudantes praticarem (CONSORTI et al., 2012). }\end{array}$ & $\begin{array}{l}\text { Consorti et al. } \\
\text { (2012). }\end{array}$ \\
\hline $\begin{array}{l}\text { Medicina } \\
\text { baseada em } \\
\text { evidências }\end{array}$ & $\begin{array}{l}\text { Os alunos trabalham em pequenos grupos, resolvendo problemas } \\
\text { contextualizados e analisando criticamente a literatura médica } \\
\text { publicada (RAMIREZ, 2015). }\end{array}$ & $\begin{array}{l}\text { Ramirez (2015); } \\
\text { Saseen et al. } \\
\text { (2017). }\end{array}$ \\
\hline $\begin{array}{l}\text { Aula } \\
\text { interativa de } \\
\text { laboratório }\end{array}$ & $\begin{array}{l}\text { É um método de comunicação bidirecional que incentiva os alunos a } \\
\text { correlacionarem as descobertas de laboratório com a sala de aula, } \\
\text { melhorando a ciência básica e o conhecimento clínico } \\
\text { (WONGJARUPONG } \text { et al., 2018). }\end{array}$ & $\begin{array}{l}\text { Wongjarupong et } \\
\text { al. (2018). }\end{array}$ \\
\hline $\begin{array}{l}\text { Aprendizagem } \\
\text { em estações } \\
\text { de trabalho }\end{array}$ & $\begin{array}{l}\text { Usado em grandes grupos de alunos e poucos instrutores, após concluir } \\
\text { todas as estações de trabalho, os alunos revisam seus conhecimentos e } \\
\text { completam testes de avaliação (GONZÁLEZ-SOLTERO et al., 2017). }\end{array}$ & $\begin{array}{c}\text { González-Soltero et } \\
\text { al. (2017). }\end{array}$ \\
\hline
\end{tabular}

Fonte: Elaborado pelos autores.

De acordo Rivkin e Gim (2013) a aula tradicional não é obsoleta, sendo essencial desenvolver a combinação de vários métodos de ensino para alcançar a melhor aprendizagem dos alunos e mantê-los engajados no curso e na profissão escolhida. Assim, professores lutam constantemente para criar cursos que possam apoiar o desenvolvimento de estratégias de aprendizagem profundas e ativas em seus alunos (MCLEAN et al., 2016). Para tanto, os tipos de metodologias ativas aqui apresentados são apenas alguns dos diversos tipos existentes para que os professores possam aperfeiçoar suas aulas e colaborar com a formação de seus alunos. 


\subsection{3 Áreas de emprego das metodologias}

Dado que o ensino de estudantes através de um método de aprendizagem ativa é eficaz (DAMNJANOVIC et al., 2012), faz-se fundamental incorporar continuamente atividades de aprendizagem ativa nos cursos, de forma que seus benefícios precisam ser compartilhados com os alunos para que eles desenvolvam uma apreciação desse método de ensino e o valor de adquirir habilidades de aprendizagem ao longo da vida (RIVKIN; GIM, 2013). Deste modo, na Tabela 4 apresenta-se as áreas em que as metodologias ativas foram empregadas na literatura.

Tabela 4 - Áreas de aplicação das metodologias encontradas

\begin{tabular}{|c|c|c|}
\hline Área & Frequência & Descrição \\
\hline $\begin{array}{c}\text { Medicina e } \\
\text { Enfermagem }\end{array}$ & $34,29 \%$ & $\begin{array}{l}\text { A educação médica está enfrentando uma crise quanto ao método de ensino } \\
\text { utilizado nas salas de aula, de modo que métodos alternativos que não exigem } \\
\text { altas taxas de comprometimento entre professores e alunos estão sendo buscados } \\
\text { para reformular os currículos destes cursos (FATMI et al., 2013). }\end{array}$ \\
\hline Engenharia & $22,86 \%$ & $\begin{array}{l}\text { Os métodos tradicionais para o treinamento de engenheiros estão sendo } \\
\text { questionados, dado os novos conhecimentos e habilidades exigidos pelo mercado } \\
\text { de trabalho (REYES; GÁLVEZ; 2010), onde o ensino efetivo de conceitos de } \\
\text { engenharia depende tanto de aulas cuidadosamente elaboradas, que atendem a } \\
\text { resultados específicos de aprendizado, como de atividades em sala que envolvam } \\
\text { ativamente os estudantes na aprendizagem (DAMNJANOVIC et al., 2012). }\end{array}$ \\
\hline Farmácia & $14,28 \%$ & $\begin{array}{l}\text { De acordo com Stewart et al. (2011) a base de conhecimento relacionado ao } \\
\text { campo da saúde continua a crescer, de modo que torna-se impossível aumentar } \\
\text { proporcionalmente o tempo ou a duração da aula presencial, de modo que os } \\
\text { docentes deverão aceitar os desafios que a nova geração de educação farmacêutica } \\
\text { apresenta, adotando, para tanto, métodos mais ativos de aprendizagem. }\end{array}$ \\
\hline $\begin{array}{l}\text { Ensino } \\
\text { básico }\end{array}$ & $4,29 \%$ & $\begin{array}{l}\text { Através das metodologias ativas, os alunos do ensino básico interagem e criam } \\
\text { conteúdos próprios relacionados a áreas curriculares com diversas vantagens, } \\
\text { tendo motivação, comprometimento, diversão e entusiasmo, mostrando melhorias } \\
\text { relacionadas ao aprendizado (LÓPEZ; GONZÁLEZ; CANO, 2016). }\end{array}$ \\
\hline Química & $2,86 \%$ & $\begin{array}{l}\text { Educadores químicos também debatem sobre o papel da sala de aula e como ela } \\
\text { pode mudar. As preocupações entre eles são de como se envolverem ativamente } \\
\text { com os alunos no processo de aprendizado. Nota-se que a cobertura de conteúdo } \\
\text { geralmente supera os alunos que participam ativamente (LUKER et al., 2015). }\end{array}$ \\
\hline Física & $1,43 \%$ & $\begin{array}{l}\text { A aprendizagem ativa em física, utilizada na concepção dos materiais e na } \\
\text { orquestração das atividades ema sala, ajuda no desenvolvimento de competências } \\
\text { dos alunos. Com a conversão do curso de aula tradicional em atividades com } \\
\text { métodos de aprendizado ativos, colaboram com a melhoria do aprendizado dos } \\
\text { alunos do curso de física (JONES; MADISON; WIEMAN, 2015). }\end{array}$ \\
\hline Odontologia & $1,43 \%$ & $\begin{array}{l}\text { Alunos do curso de odontologia avaliam que metodologias ativas apoiam o } \\
\text { processo de aprendizagem, melhorando a compreensão sobre os diversos temas, } \\
\text { como por exemplo, sobre os mecanismos dos potenciais de ação nas membranas } \\
\text { celulares, entre outros (LUCHI; MONTREZOR; MARCONDES, 2017). }\end{array}$ \\
\hline Nutrição & $1,43 \%$ & $\begin{array}{l}\text { A transição de um curso tradicional de nutrição para um curso centrado no aluno } \\
\text { baseado em metodologias ativas de aprendizagem consegue envolver os alunos } \\
\text { ativamente, incentivar a autoaprendizagem e promover o trabalho sustentado. } \\
\text { Pode ser usado como exemplo o ensino do metabolismo a estudantes de nutrição } \\
\text { e dietética (GONZÁLEZ-SANCHO et al., 2013) }\end{array}$ \\
\hline $\begin{array}{l}\text { Gestão de } \\
\text { Operações }\end{array}$ & $1,43 \%$ & $\begin{array}{l}\text { Um tipo de cenário mais ativo pode resultar em melhorias no desempenho, } \\
\text { observando que a escolha de atividades ativas pode fazer toda a diferença, } \\
\text { resultando em uma redução significativa do número de alunos e na obtenção de } \\
\text { uma taxa de aprovação mais alta no curso (SACRISTÁN-DÍAZ et al., 2015). }\end{array}$ \\
\hline
\end{tabular}

Fonte: elaborado pelos autores. 
Como observa-se, diversas são as áreas que podem empregar as metodologias ativas de ensino para melhorar o sistema de ensino e aprendizagem. Entretanto, verifica-se que a área da saúde, em cursos como medicina, enfermagem, farmácia, odontologia e nutrição, assim como a área de engenharia, são as áreas que mais demandas possuem acerca da profissionalização de seus estudantes por meio de métodos mais construtivistas de ensino. Ademais, enfatiza-se que apesar de não terem sido abordados pelos artigos analisados, outras áreas de ensino, como a áreas mais gerencial, também podem utilizar ferramentas e métodos mais dinâmicos de ensino.

\section{Considerações finais}

No método tradicional de ensino os alunos são impedidos de se verem como criadores de conhecimento, sendo apenas consumidores, de modo que as metodologias ativas de ensinoaprendizagem vêm mudar esta realidade proporcionando um maior envolvimento dos alunos, incentivando a autoaprendizagem e a criatividade. Nessa nova perspectiva, os alunos deixam de ser meros receptores de informações e passam a interagir tanto com o professor quanto com o restante da turma, de modo que as metodologias ativas permitem que eles vivenciem situações mais profundas de aprendizado.

Este artigo objetivou analisar o que tem sido publicado sobre a temática de métodos de ensino ativo no período dos últimos 10 anos, por meio de uma revisão sistemática. Para tanto, realizou-se uma análise descritiva sobre o tema abordado, caracterizando os principais achados, assim como, em seguida, uma análise semântica sobre os principais temas encontrados.

Por meio da análise descritiva foi possível perceber que o tema tem ganhado mais destaque nas publicações depois de 2015 , demonstrando ser uma temática atual e, para tanto, fundamental ser analisada. Demonstrou-se também os autores e as instituições que mais publicaram, com destaque para os autores brasileiros Fernanda K. Marcondes e Luis Henrique Montrezor, assim como para as instituições de ensino brasileiras, como Universidade Estadual de Campinas, Universidade de Araraquara e Universidade de São Paulo. Ainda, apresentou-se a origem e área de pesquisa, revistas que mais publicaram e os 10 artigos mais citados da área. Essa análise descritiva foi essencial para entender o panorama das pesquisas na área, evidenciando o Brasil como uma região que possui destaque nas pesquisas na área.

Com relação à análise semântica, foi possível evidenciar algumas características fundamentais das metodologias ativas. Entre estas verificou-se os aspectos gerais relacionados com a metodologia ativa, tais como algumas características, vantagens e dificuldades. Entre as vantagens evidenciadas, verifica-se que o aprendizado ativo cria um ambiente de classe mais aberto, colaborando com o desenvolvimento das habilidades dos alunos, como análise crítica e 
analítica, além de melhoria no desempenho dos mesmos. Com relação às desvantagens, a principal barreira se concentra no esforço docente para se adequarem a essa nova perspectiva de ensino, além de que essa metodologia exige mudanças em todo o processo de ensino, assim como um possível desinteresse dos alunos, pois exige uma maior disposição em aprender.

Ainda, evidenciou-se as metodologias ativas mais utilizadas nos estudos analisados, demonstrando que existem diversos tipos de métodos ativos que podem ser empregados na sala de aula, como forma de tornar o aprendizado dos alunos mais dinâmico. Como cada aluno possui um tipo de aprendizado diferente, cabe aos professores selecionarem métodos diversos para que os discentes consigam se adequar aos novos métodos e aprenderem fazendo.

Por fim, identificou-se as áreas de pesquisa que mais aplicam esses tipos de métodos ativos. Como evidenciado, as áreas da saúde, como medicina, enfermagem, farmácia, odontologia e nutrição, assim como a área de engenharia, possuem grande interesse em métodos construtivistas de aprendizado, demonstrando a preocupação destes cursos em um aprendizado mais ativo de seus alunos. Assim, como sugestão de pesquisas futuras recomenda-se um artigo que contemple exemplos de como a metodologia ativa pode ser aplicada a cursos gerenciais, como Administração, Contabilidade e Economia, dado que estas são áreas em constante contato com organizações, instituições e outros setores da sociedade.

Contudo, o estudo possui algumas limitações. Primeiramente, foi utilizado apenas um bando de dados para a coleta de dados, de modo que, apesar do repositório utilizado ser bem conceituado, futuras pesquisas podem abordar outras bases, como forma de contemplar mais artigos e complementar os achados aqui apresentados. Ademais, optou-se por analisar apenas artigos escritos na língua inglesa, de modo que outras pesquisas podem analisar artigos escritos em demais idiomas, como espanhol e português.

Por fim, verifica-se que o estudo revelou aspectos importantes relacionados às metodologias ativas, corroborando nessa área de estudo que, atualmente, se constitui em um dos debates mais acalorados dentro da temática de ensino. Com relação à teoria, o trabalho contribui apresentando um panorama das pesquisas na área, demonstrando seus aspectos fundamentais. Já com relação à prática, o artigo apresenta diversas metodologias que podem ser aplicadas em diversos contextos, proporcionando um primeiro caminho para profissionais que desejam trabalhar com atividades mais dinâmicas e ativas. 


\section{Referências}

AGLEN, B. Pedagogical strategies to teach bachelor students evidence-based practice: a systematic review. Nurse Education Today, United Kingdom, 2015.

ALBUQUERQUE, C. Processo ensino-aprendizagem: características do professor eficaz. Millenium-Journal of Education, Technologies, and Health, Viseu, n. 39, p. 55-71, 2016.

ALT, D. Science teachers' conceptions of teaching and learning, ICT efficacy, ICT professional development and ICT practices enacted in their classrooms. Teaching and Teacher Education, United Kingdom, v. 73, p. 141-150, 2018.

ARBELAITZ, O. et al. Analysis of introducing active learning methodologies in a basic computer architecture course. IEEE Transactions on Education, London, v. 58, n. 2, p. 110$116,2015$.

ARRUE, M.; CABALLERO, S. Teaching skills to resolve conflicts with acute confusional syndrome patients in nursing using the case method (CM). Nurse education today, United Kingdom, v. 35, n. 1, p. 159-164, 2015.

AZZALIS, L. A. et al. Integration of basic sciences in health's courses. Biochemistry and Molecular Biology Education, Malden, v. 40, n. 3, p. 204-208, 2012.

BAGHCHEGHI, N.; KOOHESTANI, H. R.; REZAEI, K. A comparison of the cooperative learning and traditional learning methods in theory classes on nursing students' communication skill with patients at clinical settings. Nurse education today, United Kingdom, v. 31, n. 8, p. 877-882, 2011.

BARBOSA, E. F.; MOURA, D. G. Metodologias ativas de aprendizagem na Educação Profissional e Tecnológica. B. Tec. Senac, Rio de Janeiro, v. 39, n. 2, p. 48-67, 2013.

BORRELL, Y. J. et al. Food control and a citizen science approach for improving teaching of Genetics in universities. Biochemistry and Molecular Biology Education, Malden, v. 44, n. 5, p. 450-462, 2016.

BUNTING, C. F.; CHEVILLE, R. A. VECTOR: A hands-on approach that makes electromagnetics relevant to students. IEEE Transactions on Education, London, v. 52, n. 3, p. 350-359, 2009.

CARPEÑO, A. et al. The key factors of an active learning method in a microprocessors course. IEEE Transactions on Education, London, v. 54, n. 2, p. 229-235, 2011.

CAVALCANTE, A. N. et al. Analysis of Bibliographic Production on Problem-Based Learning (PBL) in Four Selected Journals. Revista Brasileira de Educação Médica, Brasília, v. 42, n. 1, p. 15-26, 2018.

CHAMOSO, J. M.; CÁCERES, M. J.; AZCÁRATE, P. Reflection on the teaching-learning process in the initial training of teachers. Characterization of the issues on which pre-service mathematics teachers reflect. Teaching and Teacher Education, United Kingdom, v. 28, n. 2, p. 154-164, 2012.

CIDRAL, W. A. et al. E-learning success determinants: brazilian empirical study. Computers \& Education, United Kingdom, v. 122, n. 2 p. 273-290, 2017.

CONSORTI, F. et al. Efficacy of virtual patients in medical education: a meta-analysis of randomized studies. Computers \& Education, United Kingdom, v. 59, n. 3, p. 1001-1008, 2012. 
CRUZ, G. B. Didática e docência no ensino superior. Revista Brasileira de Estudos Pedagógicos, Brasília, v. 98, n. 250, 2017.

DAMNJANOVIC, I. et al. Educational prediction markets: construction project management case study. Journal of Professional Issues in Engineering Education and Practice, Reston, v. 139, n. 2, p. 134-138, 2012.

DAOUK, Z.; BAHOUS, R.; BACHA, N. N. Perceptions on the effectiveness of active learning strategies. Journal of Applied Research in Higher Education, New York, v. 8, n. 3, p. 360-375, 2016.

DE JUSTO, E.; DELGADO, A. Change to competence-based education in structural engineering. Journal of Professional Issues in Engineering Education and Practice, Reston, v. 141, n. 3, 2015.

DEREVENSKAIA, O. Active learning methods in environmental education of students. Procedia - Social and Behavioral Sciences, United Kingdom, v. 131, p. 101-104, 2014.

DIAS, G. P. P.; SAUAIA, A. C. A.; YOSHIZAKI, H. T. Y. Estilos de aprendizagem FelderSilvermaneo aprendizado com jogos de empresa. RAE-Revista de Administração de Empresas, São Paulo, v. 53, n. 5, p. 469-484, 2013.

DOMÍNGUEZ, C.; JAIME, A. Database design learning: A project-based approach organized through a course management system. Computers \& Education, United Kingdom, v. 55, n. 3, p. 1312-1320, 2010.

FATMI, M. et al. The effectiveness of team-based learning on learning outcomes in health professions education: BEME Guide. Medical teacher, Dundee, v. 35, n. 12, p. 1608-1624, 2013.

FORNI, M. F. et al. An active-learning methodology for teaching oxidative phosphorylation. Medical education, Oxford, v. 51, n. 11, p. 1169-1170, 2017.

FREITAS, H. C. L. et al. Formação de professores no Brasil: 10 anos de embate entre projetos de formação. Educação \& Sociedade, Campinas,v. 23, n. 80, 2002.

GAHUTU, J. B. Physiology teaching and learning experience in a new modular curriculum at the National University of Rwanda. Advances in physiology education, Rockville, v. 34, n. 1, p. 11-14, 2010.

GARCÍA, J.; HERNANDEZ, A. Active methodologies in a queueing systems course for telecommunication engineering studies. IEEE Transactions on Education, London, v. 53, n. 3, p. 405-412, 2010.

GONZÁLEZ-SANCHO, J. M. et al. The use of an active learning approach to teach metabolism to students of nutrition and dietetics. Biochemistry and Molecular Biology Education, Malden, v. 41, n. 3, p. 131-138, 2013.

GONZÁLEZ-SOLTERO, R. et al. Work station learning activities: a flexible and scalable instrument for integrating across basic subjects in biomedical education. BMC medical education, United Kingdom, v. 17, n. 1, p. 236, 2017.

GUSC, J.; VAN VEEN-DIRKS, P. Accounting for sustainability: an active learning assignment. International Journal of Sustainability in Higher Education, [s. 1.], v. 18, n. 3, p. 329-340, 2017.

JONES, D. J.; MADISON, K. W.; WIEMAN, C. E. Transforming a fourth year modern optics course using a deliberate practice framework. Physical Review Special TopicsPhysics Education Research, Washington, v. 11, n. 2, p. 020108- 020116, 2015. 
KAILA, E. et al. Redesigning an object-oriented programming course. ACM Transactions on Computing Education (TOCE), New York, v. 16, n. 4, p. 18, 2016.

KILGOUR, J. M.; GRUNDY, L.; MONROUXE, L. V. A rapid review of the factors affecting healthcare students' satisfaction with small-group, active learning methods. Teaching and Learning in Medicine, Springfield, v. 28, n. 1, p. 15-25, 2016.

KRUPAT, E. et al. Assessing the effectiveness of case-based collaborative learning via randomized controlled trial. Academic Medicine, Washington, v. 91, n. 5, p. 723-729, 2016.

LEITE, L. et al. "Sustainability On Earth" WebQuests: do they qualify as problem-based learning activities? Research in Science Education, Victória, v. 45, n. 1, p. 149-170, 2015.

LIMA, V. V. Constructivist spiral: an active learning methodology. Interface, Botucatu, v. 21, n. 61, p. 421-34, 2017.

LÓPEZ, J. L. G. et al. Active methodology in the audiovisual communication degree.

Procedia Social and Behavioral Sciences, United Kingdom, v. 2, n. 2, p. 4487-4491, 2010.

LÓPEZ, J. M. S.; GONZÁLEZ, M. R.; CANO, E. V. Visual programming languages integrated across the curriculum in elementary school: A two year case study using "Scratch" in five schools. Computers \& Education, United Kingdom, v. 97, p. 129-141, 2016.

LUCHI, K. C. G.; MONTREZOR, L. H.; MARCONDES, F. K. Effect of an educational game on university students' learning about action potentials. Advances in physiology education, Rockville, v. 41, n. 2, p. 222-230, 2017.

LUKER, C. et al. Introduction to the Spring 2014 Conf. Chem on the flipped classroom. Journal of Chemical Education, Iowa, v. 92, n. 9, p. 1564-1565, 2015.

MACDOUGALL, C. A novel teaching tool combined with active-learning to teach antimicrobial spectrum activity. American Journal of Pharmaceutical Education, Arlington, v. 81, n. 2, 2017.

MACEDO, K. D. da S. et al. Active learning methodologies: possible paths to innovation in health teaching. Escola Anna Nery, Rio de Janeiro, v. 22, n. 3, 2018.

MACVAUGH, J.; NORTON, M. Introducing sustainability into business education contexts using active learning. International Journal of Sustainability in Higher Education, [s. 1.], v. 13, n. 1, p. 72-87, 2012.

MAIA, M. C. Entendendo a necessidade de renovação no processo de ensino e aprendizagem. RAE-Eletrônica, São Paulo, v. 9, n. 1, p. 1, 2010. Disponível em: https://rae.fgv.br/rae-eletronica/vol9-num1-2010/entendendo-necessidade-renovacao-noprocesso-ensino-aprendizagem. Acesso em: 10 jul. 2018.

MARCONDES, F. K. et al. A puzzle used to teach the cardiac cycle. Advances in physiology education, Rockville, v. 39, n. 1, p. 27-31, 2015.

MARIN, M. J. S. et al. Aspectos das fortalezas e fragilidades no uso das metodologias ativas de aprendizagem. Revista Brasileira de Educação Médica, Brasília, v. 34, n. 1, p. 13-20, 2010.

MCCORMACK, O.; O'FLAHERTY, J. An examination of pre-service teachers' attitudes towards the inclusion of development education into Irish post-primary schools. Teaching and teacher education, United Kingdom, v. 26, n. 6, p. 1332-1339, 2010. 
MCFEE, R. M. et al. Use of case-based or hands-on laboratory exercises with physiology lectures improves knowledge retention, but veterinary medicine students prefer case-based activities. Advances in physiology education, Rockville, v. 42, n. 2, p. 182-191, 2018.

MCLEAN, S. et al. Flipped classrooms and student learning: not just surface gains. Advances in physiology education, Rockville, v. 40, n. 1, p. 47-55, 2016.

MELO PRADO, H. et al. Active learning on the ward: outcomes from a comparative trial with traditional methods. Medical education, Oxford, v. 45, n. 3, p. 273-279, 2011.

MELO, B. de C.; SANT'ANA, G. A prática da Metodologia Ativa: compreensão dos discentes enquanto autores do processo ensino-aprendizagem. Comun. ciênc. saúde, Brasília, v. 23, n. 4, p. 327-339, 2012.

MENEKSE, M. et al. Differentiated overt learning activities for effective instruction in engineering classrooms. Journal of Engineering Education, Washington, v. 102, n. 3, p. 346-374, 2013.

MISSEYANNI, A. et al. Active learning stories in higher education: lessons learned and good practices in STEM Education. In: MISSEYANNI, A. (ed.). Active learning strategies in higher education: teaching for leadership, innovation, and creativity. Bingley: Emerald Publishing, 2018. p. 75-105.

MITRE, S. M. et al. Metodologias ativas de ensino-aprendizagem na formação profissional em saúde: debates atuais. Ciênc. Saúde coletiva, Rio de Janeiro, v. 13, n. 2, p. 2133-2144, 2008.

MONTREZOR, L. H. Performance in physiology evaluation: possible improvement by active learning strategies. Advances in physiology education, Rockville, v. 40, n. 4, p. 454-457, 2016.

MORGAN, H. et al. The flipped classroom for medical students. The Clinical Teacher, Oxford, v. 12, n. 3, p. 155-160, 2015.

MOURTHÉ JUNIOR, C. A.; LIMA, V.; PADILHA, R. Q. Integrating emotions and rationalities for the development of competence in active learning methodologies. Interface, Botucatu, v. 22, n. 65, p. 577-588, 2018.

NASCIMENTO, G. V. P. Estudo controlado da efetividade de um instrumento que acopla aprendizagem ativa e tecnologia: criação de vídeos pelos estudantes. 2014. Dissertação (Mestrado em Ciências e Tecnologias em Saúde) - Universidade de Brasília, Brasília, 2014.

PINTO, A. S. da S. et al. Inovação didática - projeto de reflexão e aplicação de metodologias ativas de aprendizagem no ensino superior: uma experiência com "peerinstruction". Janus, Lorena, v. 9, n. 15, p. 75-87, 2012.

RAMIREZ, B. U. Correlation of self-assessment with attendance in an evidence-based medicine course. Advances in physiology education, Rockville, v. 39, n. 4, p. 378-382, 2015.

REGUERAS, L. M. et al. Effects of competitive e-learning tools on higher education students: A case study. IEEE Transactions on Education, London, v. 52, n. 2, p. 279-285, 2009.

REYES, E.; GÁLVEZ, J. C. Introduction of innovations into the traditional teaching of construction and building materials. Journal of Professional Issues in Engineering Education and Practice, Reston, v. 137, n. 1, p. 28-37, 2010. 
RIVKIN, A.; GIM, S. Student preferences regarding teaching methods in a drug-induced diseases and clinical toxicology course. American journal of pharmaceutical education, Arlington, v. 77, n. 6, p. 123, 2013.

RODRIGUEZ-ANDARA, A. et al. Roadmapping towards sustainability proficiency in engineering education. International Journal of Sustainability in Higher Education, [s. 1.], v. 19, n. 2, p. 413-438, 2018.

SACRISTÁN-DÍAZ, M. et al. The effects of teaching and assessment methods on academic performance: a study of an Operations Management course. Innovations in Education and Teaching International, London, v. 53, n. 5, p. 497-507, 2015.

SASEEN, J. J. et al. A pharmacotherapy capstone course to target student learning and programmatic curricular assessment. American Journal of Pharmaceutical Education, Arlington, v. 81, n. 3, p. 45, 2017.

SEMAN, L. O. et al. On the students' perceptions of the knowledge formation when submitted to a Project-Based Learning environment using web applications. Computers \& Education, United Kingdom, v. 117, p. 16-30, 2018.

SINGER, F. M.; MOSCOVICI, H. Teaching and learning cycles in a constructivist approach to instruction. Teaching and Teacher Education, United Kingdom, v. 24, n. 6, p. 1613 1634, 2008.

SOBRAL, F. R.; CAMPOS, C. J. G. Utilização de metodologia ativa no ensino e assistência de enfermagem na produção nacional: revisão integrativa. Revista da Escola de Enfermagem da USP, São Paulo, v. 46, n. 1, p. 208-218, 2012.

SPENCER, C.; BANDY, K. Using Hand Signs to Teach HIV Medications. American journal of pharmaceutical education, Arlington, v. 82, n. 1, p. 6292, 2018.

SRIVASTAVA, S. K.; TAIT, C. An activity-based learning approach for key geographical information systems (GIS) concepts. Journal of Geography in Higher Education, Gloucestershire, v. 36, n. 4, p. 527-545, 2012.

STEWART, D. W. et al. Active-learning processes used in US pharmacy education. American journal of pharmaceutical education, Arlington, v. 75, n. 4, p. 68, 2011.

TAN, N. et al. A controlled study of team-based learning for undergraduate clinical neurology education. BMC medical education, United Kingdom, v. 11, n. 1, p. 91, 2011.

TORRACO, R. J. Writing Integrative Literature Reviews: Guidelines and Examples. Human Resource Development Review, Eastleigh, v. 4, n. 3, 2005.

URIAS, G. M. P. C.; AZEREDO, L. A. S. Metodologias ativas nas aulas de Administração Financeira: alternativa ao método tradicional de ensino para o despertar da motivação intrínseca e o desenvolvimento da autonomia. Administração: Ensino e Pesquisa, São Paulo, v. 18, n. 1, p. 39-67, jan. 2017.

VALENZUELA-VALDÉS, J. F. et al. Low cost ubiquitous context-aware wireless communications laboratory for undergraduate students. IEEE Transactionson Learning Technologies, London, v. 9, n. 1, p. 31-36, 2016.

VALES, J. F.; SANTOS, N. V. Metodologia ativa como ferramenta de ensino e aprendizagem no curso técnico de logística. South American Development Society Journal, São Paulo, v. 4, n. 10, p. 146-155, 2018. 
VERGARA, S. C. Repensando a relação ensino-aprendizagem em administração: argumentos teóricos, práticas e recursos. Organizações e Sociedade, Salvador, v. 10, n. 28, p. 131$142,2003$.

WONGJARUPONG, N. et al. Interactive laboratory classes enhance neurophysiological knowledge in Thai medical students. Advances in physiology education, Rockville, v. 42, n. 1, p. 140-145, 2018.

ZANI, A. V.; NOGUEIRA, M. S. Incidentes críticos do processo ensino-aprendizagem do curso de graduação em enfermagem, segundo a percepção de alunos e docentes. Revista Latino-Americana de Enfermagem, Ribeirão Preto, v. 14, n. 5, 2006.

ZINGONE, M. M. et al. Comparing team-based and mixed active-learning methods in an ambulatory care elective course. American journal of pharmaceutical education, Arlington, v. 74, n. 9, p. 160, 2010.

ZUPIC, I.; CATER, T. Bibliometric Methods in Management and Organization. Organizational Research Methods, Westchester, v. 18, n. 3, 2015. 